\title{
Guest Editorials \\ Susceptibility Genetics in the Etiopathogenesis of Alzheimer's Disease: Role for Potential Confounding Factors
}

Finding genetic linkage and identifying the genes responsible for disease can revolutionize our understanding of disorders with obscure or complex etiology and pathogenesis (Weatherall, 1991). When relevant genes have been cloned, the identification of specific mutations that cause disease (Goate et al., 1991) enables molecular pathogenesis of the condition to be addressed.

The known genetic causes of Alzheimer's disease (AD), which include mutations in the APP gene and two presenilin genes, are rare and account for approximately $5 \%$ to $15 \%$ of all cases (Tanzi et al., 1996). These rare mutations are transmitted as autosomal dominant traits. In contrast, the majority of cases of AD are sporadic and generally of late onset, occurring after 65 years of age. Although much can be learned from the studies of mutations in the APP and presenilin genes, the molecular basis of sporadic $A D$ is more complex. Whereas single gene defects that exert a major effect are rare but specific causes of $A D$, the majority of cases probably arise as the result of several polygenes, each making a comparatively small contribution toward the phenotype. Two main strategies exist for identifying candidate genes. The first is to perform linkage analysis based on $A D$ pedigrees. The second is to carry out association studies on samples from the general population. The latter approach was used to identify apolipoprotein E polymorphisms (APOE, gene; apoE, protein) as a risk factor for $\mathrm{AD}$. Other irregular patterns of transmission can be observed. These include mitochondrial inheritance, genomic imprinting, and so-called dynamic mutations that lead to the phenomenon of anticipation, as observed in Huntington's disease.

Allen Roses (1997) reviewed the findings with APOE in the context of the pathogenesis of AD. Much remains, however, to be understood about those variables that may contribute to the central pathological changes of $A D$, namely neuritic plaques and neurofibrillary tangles. In this article, we discuss this in detail with special reference to the APOE polymorphism and potential confounding factors.

\section{APOLIPOPROTEIN E AND ALZHEIMER'S DISEASE}

An association between the apolipoprotein $E \& 4$ allele and $A D$ was first demonstrated by Strittmatter and colleagues (1993). 
Whereas linkage represents a relationship with a specific chromosomal locus, association is a relationship between common functional variations (allelic polymorphisms) in a susceptibility gene that is present in the general population. Although there may be some minor ethnic variations (Hendrie et al., 1995; Maestre et al., 1995), similar APOE genotype distribution for patients with $A D$ in populations of diverse ethnic backgrounds suggests that it is the $\varepsilon 4$ allele that is directly responsible for its association with $A D$. A decreased risk of AD in those with an $\varepsilon 2$ allele suggests that it is due to the APOE gene rather than a nearby gene in linkage dysequilibrium. Tests for association between particular polymorphisms and disease phenotype require large numbers of unrelated affected patients. Although many studies have now confirmed the APOE association in AD, testing populations for APOE genotype cannot be used to predict development of $A D$; presence of the $\varepsilon 4$ allele is neither necessary nor sufficient to cause disease. Furthermore, it should be noted that distribution of the $\varepsilon 4$ allele varies considerably among different populations (Utermann, 1994).

ApoE is a plasma protein that is involved in cholesterol transport. The APOE $\varepsilon 4$ allele is overrepresented in $A D$ patients with late-onset symptoms, and APOEgenotype represents an important biological marker for the disease, accounting for $45 \%$ to $60 \%$ of the genetic component of $\mathrm{AD}$ (Nalbantoglu et al., 1994).

Possible biological explanations for the association of APOE genotype with AD have included isoform-specific neurotoxic and/or neuroprotective effects of apoE and the binding of apoE to $A \beta$ or tau proteins in an isoform-dependent fashion (Strittmatter et al., 1994). Alter- natively, apoE might influence neuritic outgrowth: Whereas apoE3 stimulates outgrowth in cell culture, apoE4 has the converse effect (Nathan et al., 1994). At present, however, these explanations remain hypotheses whose relevance in vivo has yet to be established.

Before these hypotheses can be proven, a number of issues need to be addressed and which are discussed below. First, the specificity of the association between APOE genotype and various neurodegenerative, neurological, and psychiatric disorders remains uncertain. Second, does APOE genotype affect the pathology of AD? Third, are there any genetic interactions with APOE genotype? Finally, to what extent does apoE influence nonspecific factors that may or may not affect the development or progression of disease? With respect to the latter, particular concern is given to the role of cerebrovascular diseases and how they might impinge on the development of $\mathrm{AD}$ and its association with the APOE4 genotype.

\section{SPECIFICITY OF THE APOLIPOPROTEIN E ASSOCIATION}

Possession of an APOE $\varepsilon 4$ allele is neither necessary nor sufficient for the development of $A D$, and the lifetime risk of $A D$ in patients with an $\varepsilon 4$ allele remains less than 1 in 3 for those without a family history of dementia (Seshadri et al., 1995). In addition to $A D$, the APOE $\varepsilon 4$ allele is overrepresented in vascular dementia (see below), Pick's disease (Farrer et al., 1995), sporadic frontal lobe dementia (Stevens et al., 1997), and dementia with Lewy bodies (Galasko et al., 1994; Harrington et al., 1994). These findings suggest that apoE4 can influence the risk of dementias that 
have clearly distinct pathogenesis and patterns of clinical expression. Thus there is still uncertainty over the specificity of the APOE effect. Likewise, results from a population-based study indicated that the prevalence of dementia in $\mathrm{E} 4$ / $\mathrm{E} 4 \mathrm{ho}$ mozygotes by the age of 90 years reached only $50 \%$ (Henderson et al., 1995), emphasizing that apoE4 is insufficient on its own to cause either dementia or AD.

$A D$ is associated with substantial neuronal loss and up to $65 \%$ of cortical neurons may die. There has not been a detailed study in which the influence of APOE genotype on neuronal loss has been studied in $A D$, in other neurodegenerative or psychiatric disorders, or in normal mental aging. This is important in relation to the purported specificity of the APOE association. The mechanism by which APOE exerts its influence on $A D$ is not known. A consistent increase in the deposition of $A \beta$ that is linked to increasing $\varepsilon 4$ gene dosage (Gomez-Isla, 1996; Polvikoski et al., 1995; Rebeck et al., 1993), that is not due to a differential survival effect (Corder et al., 1995). Duration and progression of $A D$ are not related to APOE4, suggesting that the higher $A \beta$ load is not a major determinant of the course of the disease. This is consistent with better correlations that are observed between cognitive impairment and neuronal loss, neurofibrillary pathology, and synapse loss (Arriagada et al., 1992; Terry et al., 1991; Wilcock \& Esiri, 1982). The marked synaptic pathology in AD does not differ between patients with and without the $\varepsilon 4$ allele (Blennow et al., 1996) and there is no correlation between overall levels of apoE and synaptophysin-immunoreactivity or amyloid load in the brain (Pirttilä et al., 1996b). Evidence to provide a link between neurofibrillary pathology and APOE4 (Nagy et al., 1995; Ohm et al., 1995; Sparks et al., 1996) has not been established by others (Harrington et al., 1994; Landén et al., 1996; Rebeck et al., 1993; Sparks et al., 1996). Furthermore, patients with dementia with Lewy bodies, whose brains are characterized by minimal neurofibrillary pathology, share a similarly elevated $\varepsilon 4$ allele frequency with that observed in $\mathrm{AD}$ (Harrington et al., 1994; Morris et al., 1996).

If apoE had a general role in the central nervous system (CNS) response to injury, then it would be predicted that APOE genotype may affect the onset or course of neurodegenerative disorders other than AD or acute CNS trauma. APOE4 is not associated with Parkinson's disease, Huntington's disease, amyotrophic lateral sclerosis, Down's syndrome, or hippocampal dementia. However, it may serve as a risk factor in the recovery from head trauma (Nicoll et al., 1995; Sorbi et al., 1995) and APOE4 is associated with a poor outcome following intracerebral hemorrhage (Alberts et al., 1995). Recovery following coronary bypass surgery is influenced also by a variety of factors including APOE genotype.

Depressed people often show a nonspecific cognitive impairment that, in general, responds to treatment. Krishnan and colleagues (1996) found an association between APOE4 and depression. Steffens and colleagues (1997), in contrast, reported that a history of late-onset depression was a risk factor for $A D$ but that it was independent of APOE genotype. Similarly, elderly depressed patients with cognitive impairment are more at risk of developing $\mathrm{AD}$ by an APOE4-independent pathway than patients with psychotic symptoms (Zubenko et al., 1996). APOE4, therefore, may be either a risk factor for psychotic de- 
pression in late life or the symptoms may represent an early manifestation of AD. Some studies have reported that APOE genotype distribution is altered in patients with schizophrenia, but the findings have been contradictory. APOE4 was decreased in patients with late paraphrenia (Howard et al., 1995), increased in schizophrenic patients (Harrington et al., 1995), and associated with a younger age of onset of schizophrenia in an elderly population in which Alzheimer pathology was increased to an extent that remained insufficient to confer a diagnosis of AD (Arnold et al., 1997). In these studies, it is likely that the complex genetics and imprecise diagnosis of schizophrenia contributed to the apparent discrepancies.

\section{APOE GENOTYPE AND ITS INTERACTION WITH OTHER GENES}

Mutations in the APP gene (Goate et al., 1991) and in two presenilin genes (LevyLahad et al., 1995; Rogaev et al., 1995; Sherrington et al., 1995) are sufficient to cause AD in the familial forms of the disease. To date, 56 independent mutations, which segregate with $A D$, have been reported in these three genes. Nonetheless, a genetic cause in perhaps as many as half of the early, familial AD cases has yet to be found (Tanzi et al., 1996). Although some of these mutations are associated with minor differences in clinical presentation, the pathological changes at autopsy remain relatively constant. The major differences are observed in age of onset and rate of progression of the disease. In contrast, and as described by Allen Roses (1997), APOE is a susceptibility locus: Each dose of $\varepsilon 4$ increases the risk and lowers the age-of-onset distribution.
APOE genotype appears to have no effect on the phenotype of PS1 mutations (Tanzi et al., 1996). This is in contrast to the situation with APP, where APOE genotype appears to affect both age of onset and the degree of amyloid burden in carriers with APP mutations (Sorbi et al., 1995).

An explanation is needed for the $a b$ sence of any APOE4 homozygotes in Down's syndrome (Van Gool et al., 1995), a family history of which serves as a recognized risk factor for $A D$. It could be due to decreased survival, embryonic lethality, or some other unidentified factor. Elderly patients with Down's syndrome develop AD pathology and frequently become demented.

Clarification of the overall effect of APOE genotype on survival is essential. Although absence of the $\varepsilon 4$ allele is associated with longevity (Schächter et al., 1994), it is still important to study those genotypes associated with longevity alongside disease-specific analyses, as discussed by Galinsky and colleagues (1997).

Associations between other genetic polymorphisms and AD, e.g., $\alpha_{1}$-antichymotrypsin (Kamboh et al., 1995), very-lowdensity lipoprotein receptor (Okuizumi et al., 1995), and the putative protective effect of a nonamyloid component precursor polymorphism (Xia et al., 1996) have not been established in subsequent investigations and so the role of such factors remains equivocal. Whether they play a role in a subset of AD patients cannot be excluded. Recent evidence indicates that the $\mathrm{K}$ variant of butyrylcholinesterase, or a nearby gene on chromosome 3 , acts in synergy with APOE $\varepsilon 4$ as a further susceptibility locus for late-onset AD (LOAD) (Lehmannet al.,1997). The possibility that mitochondrial DNA mutations may be associated with a subset of AD (Hutchin 
\& Cortopassi, 1995) suggests that these may affect the bioenergetic capacity of neurons (Wallace, 1994). Recently, mutations in mitochondrial cytochrome $c$ oxidase $(\mathrm{CO})$ genes $\mathrm{CO} 1$ and $\mathrm{CO} 2$ have been shown to segregate with late-onset $A D$ and these are genes that are defective in the AD brain (Davis et al., 1997). These genes are maternally inherited, but there is no evidence that they are influenced by APOE genotype (Davis et al., 1997).

The extent of the $\varepsilon 4$ effect is diminished in the very elderly (Rebeck et al., 1994; Sobel et al., 1995) and many can reach old age without cognitive impairment despite the inheritance of one or two APOE $\varepsilon 4$ alleles (Hyman et al., 1996). Use of APOE genotype in predictive test situations, however, requires absolute risk information that can be obtained only from prospective cohort studies, a number of which are under way (Brayne et al., 1996; Feskens et al., 1994; Henderson et al., 1995; Hyman et al., 1996; Kuusisto et al., 1994; Myers et al., 1996; Petersen et al., 1995). Increased periods of follow-up investigation and information in the elderly need to be addressed further. However, the effect of APOE genotype on cognitive function in early life also merits consideration in light of recent results from a study of octogenarian twins. The findings indicate that the genetic contribution to general cognitive ability is fairly constant throughout life (McClearn et al., 1997). In this respect, it will be of interest to discover the variety of genes that contribute to cognitive ability and how each of their products interacts with each other or with apoE in both normal aging and AD.

Roses (1997) has described the need for clinicians to understand the diagnostic and predictive uses for susceptibility genes that are not the sole determinant for disease. He emphasized that these are not the same as tests for specific mutations that might cause disease. Although this is true for many complex disorders, including $A D$, due caution needs to be exercised in understanding the mechanism by which and to what extent particular susceptibility genes determine the course of the disease. If further susceptibility genes are to be identified, it is even more important that potential confounding factors are addressed. The mechanisms by which susceptibility factors exert their effect on $A D$ may provide therapeutic approaches both at the molecular level and, perhaps, in the area of dealing with avoidable or treatable risk factors that become apparent through appropriate case-control, risk-assessment studies.

\section{CONFOUNDING FACTORS IN SUSCEPTIBILITY POLYMORPHISMS}

Another major issue concerns the full scope of confounding factors that might be influenced by APOE genotype. A list of potential factors that may or may not influence the progression and development of $A D$ is shown in Table 1. Although some of these factors have been considered in relation to APOE genotype (e.g., gender, age, head trauma, and others), more have yet to be examined. The factors listed have been split into three categories. Numerous biological factors may influence $A D$ and some of these are discussed later.

Sociological factors may be directly relevant to $A D$ or might act as surrogate markers of some other process with a genetic component (e.g., educational level may reflect intellect, a complex phenomenon with a substantive genetic input). 
TABLE 1. Putative Risk Factors That May Confound the Influence of APOE Polymorphism on Development and Progression of Alzheimer's Disease

Biological
Family history of dementia or Down's
syndrome
Increased age
Late maternal age
Gender/estrogen
Ethnicity
Hyperthyroidism
Cardiovascular and cerebrovascular disease
Respiratory disease
Hypertension
Depression
Diabetes mellitus
Autoimmune diseases; rheumatoid arthritis
Osteoporosis
Renal disease
Carcinoma
Sociological
Level of education
Environmental
Head trauma
Smoking
Pharmacological treatments
Infectious diseases
Heavy metal exposure
Aluminum

Note. Inclusion of items on this list does not necessarily indicate that it is an established risk factor for Alzheimer's disease.

The strongest evidence that nongenetic, environmental factors are involved in $\mathrm{AD}$ comes from the observation that some monozygotic twin pairs, including shared $\varepsilon 4$ alleles, have remained discordant for $A D$ for up to 20 years (Breitner et al., 1995). In certain instances, the identification that such confounding factors are involved would offer the possibility for preventive and / or therapeutic intervention. Thorough analysis of all diseases associated with $A D$ at death and during life needs to be performed in prospective epidemiological surveys. AD is associat- ed frequently with somatic disease at death: Two thirds of patients with brains severely damaged by AD had suffered significant cardiac disease, chronic bronchitis, or other ill health during life (Blessed, 1984). Such disorders have not been systematically investigated in relation to APOE status. Furthermore, it is not known how individual diseases may affect the duration of AD or an individual's life expectancy. APOE genotype does not affect the progression or duration of cognitive impairment or AD (Corder et al., 1995; Growdon et al., 1996; Kurz et al., 1996). To elicit an answer to such questions requires comparative studies of the development or progression of $\mathrm{AD}$ in those patients with and those without an $\varepsilon 4$ allele. This presents a daunting task for which adequate sample sizes are essential (Smith \& Day, 1984). Many conflicting reports, based upon small sample numbers, have appeared over the last 4 years in connection with the association between various disorders and APOE genotype distribution. Extensive multicenter epidemiological studies would be one way to address this issue.

\section{CEREBROVASCULAR AND CARDIOVASCULAR DISEASE}

Vascular dementia accounts for up to $25 \%$ of dementia cases. It is a complex concept because of the diverse vascular mechanisms that can lead to cognitive impairment (white-matter lesions, restricted cerebral blood flow, cerebral amyloid angiopathy [CAA]) and difficulties in the differential diagnosis of $\mathrm{AD}$ and vascular dementia. Cerebrovascular disease and vascular dementia are associated with an overrepresentation of the $\varepsilon 4$ allele (Frisoni et al., 1994; Myers 
et al., 1996; Noguchi et al., 1993; Slooter et al., 1997). Some studies, however, have failed to confirm this association (Bétard et al., 1994; Scacchi et al., 1995; Higuchi et al., 1996; Pirttilä et al., 1996a; Sulkava et al., 1996). In a community-based study, cerebrovascular disease and APOE4 appeared to have a synergistic effect on cognitive decline in the elderly (Kalmijn et al., 1996). Isoe and colleagues (1996) reported an overrepresentation of the $\varepsilon 4$ allele in AD and vascular dementia, but not in the nondemented patients with cerebrovascular disease. This suggests that APOE can influence the development of dementia (not specifically AD) independently of any effect on the development of atherosclerosis. Data from a recent cross-sectional population study indicate that atherosclerosis is associated not only with vascular dementia, but with AD as well (Hofman et al., 1997). An interaction between atherosclerosis and APOE genotype was also found: Increased prevalence of $A D$ with atherosclerosis was most pronounced in those possessing an $\varepsilon 4$ allele (Hofman et al., 1997).

Epidemiological data on vascular dementia are, however, both sparse and of poor reliability (Rocca et al., 1991). Rigorous pathological confirmation is rarely available. In general, strokes that contribute to more than $80 \mathrm{~cm}^{3}$ loss of brain tissue lead to vascular dementia. However, it is unclear to what extent small-vessel damage contributes to or exacerbates the development of $\mathrm{AD}$. Alzheimer pathology may be directly linked to microvascular changes: Amyloid deposits in leptomeningeal and cortical arterioles may result in leakage (Esiri, 1994).

The $\varepsilon 4$ allele is a significant factor in development of CAA in AD and in dementia with Lewy bodies (Kalaria \&
Premkumar, 1995; Lippa et al., 1995), and a high proportion of $\varepsilon 4$ carriers with AD have severe arteriosclerosis (Kalaria, 1997). The $\varepsilon 4$ allele is also a risk factor for CAA, independent of its association with AD (Greenberg, 1995). Nicoll and colleagues (1997) provide evidence for further complexity. These authors found that the APOE $\varepsilon 2$ allele, but not the $\varepsilon 4$ allele, served as a risk factor for cerebral hemorrhage due to CAA. CAA causes 10\% to $15 \%$ of cases of spontaneous cerebral hemorrhage in the elderly, and it was suggested that the $\varepsilon 2$ allele may act as a risk factor for the rupture of amyloidladen blood vessels. This study also demonstrates that, despite similarities in the vascular deposition of $A \beta$ in CAA and $A D$, the former shows important differences from $A D$ need to be understood.

The extent of increase in the $\varepsilon 4$ allele frequency in vascular dementia is not as great as that observed in AD but is nevertheless comparable with the statistically significant increases observed for coronary artery disease in nondemented adults (Cumming \& Robertson, 1984; Davignon et al., 1988; Kuusi et al., 1989; Van Bockxmeer \& Mamotte, 1992). Thus cardiovascular disease needs to be taken into consideration in addition to vascular disease that affects the brain.

Estrogen is a gender-specific factor that may modify genetic influences. Previous reports have suggested that estrogen replacement therapy may exert a protective effect on the risk of women developing AD (Henderson, 1997). Reduced penetrance of $A D$ in men may reflect confounding relationships between cardiovascular disease and APOE4. Inheritance of APOE 4 confers risk of ischemic heart disease in middle-aged men (Cumming \& Robertson, 1984) but not in the elderly (Ku usisto et al., 1994), and APOE4 
is less frequent in men than in women. The maximum effect is observed below the age of 70 years. In one study, 15 unaffected E4/E4 homozygous subjects were older than their affected siblings (Blacker et al., 1997). These findings may account for the higher age-specific prevalence of $\mathrm{AD}$ in women.

\section{POLYGENIC INTERACTIONS}

The APOE polymorphism provides one susceptibility gene for AD. Tanzi and colleagues (1996) and the team at Duke University (Larkin, 1997) have identified a second susceptibility gene for AD that is located on chromosome 12 , which reaffirms that $A D$ is both a complex and heterogeneous disorder. Whether other susceptibility genes are yet to be identified remains to be found.

In a recent preliminary study, the frequency distribution of certain HLA-DR antigen types has been reported to differ between patients with late-onset AD and controls (Curran et al., 1997). This was only evident in the absence of APOE $\varepsilon 4$ alleles. Whereas the combined frequencies of DR1, 2, and 3 accounted for $67 \%$ of the total DR antigens in the AD group, they only represented $28 \%$ in the control group. DR4 and 6 were present at a lower frequency in $\mathrm{AD}$. Although the findings of this study need to be replicated, it suggests that DR antigen type may serve as a susceptibility factor for AD and, in particular, in those patients not influenced by APOE $\varepsilon 4$ genotype. Furthermore, it is possible that the HLA-DR association may account for the inverse association that has been reported between rheumatoid arthritis and $A D$; rheumatoid arthritis is associated with frequencies of $60 \%$ to $70 \%$ for the DR4 allele. A simplified scheme to represent these interconnecting factors is shown in Figure 1. As depicted, a clear APOE4-dependent distribution is suggested by the data. Studies in which APOE genotype is not taken into consideration (e.g., those undertaken prior to 1993) are liable to give erroneous findings if the factor under consideration is either dependent upon or independent of a specific APOE genotype. In the example shown, LOAD patients with the $\varepsilon 4$ allele might mask the HLA-DR/AD association.

Payami and colleagues (1997) reported that the HLA-A2 allele is associated with an earlier onset age of AD in excess of that conferred by the APOE $\varepsilon 4$ allele. Further studies are needed to confirm these findings and to determine whether the association is with the HLA gene or another nearby gene in the chromosome $6 \mathrm{p} 21.3$ region. The possible association of $A D$ with HLA antigens would support roles for the immune/inflammatory response being involved in AD (Breitner, 1996).

\section{COMORBIDITY}

Many illnesses might contribute significant, though small, contributions to the development of AD. A number of these have been listed in Table 1 and some are found with regularity in patients with AD who undergo autopsy. Concomitant ill health and AD need to be studied further.

Inconclusive results for the association between diabetes and AD (Finch \& Cohen, 1997; Leibson et al., 1997) may reflect problems involved in analysis and difficulties in diagnosis. Type I insulin-dependent diabetes mellitis involves autoimmune destruction of pancreatic islets and is associated with HLA-DR3 and -DR4 anti- 
gens (Todd et al., 1987), whereas the more frequent, adult-onset type II disease shows no HLA association.

Data suggest that the $\varepsilon 4$ allele may be protective against the development of adenoma and carcinoma of the proximal, but not distal, colon (odds ratio = .35; Kervinen et al., 1996). Whether APOE influences CNS tumors is not known.

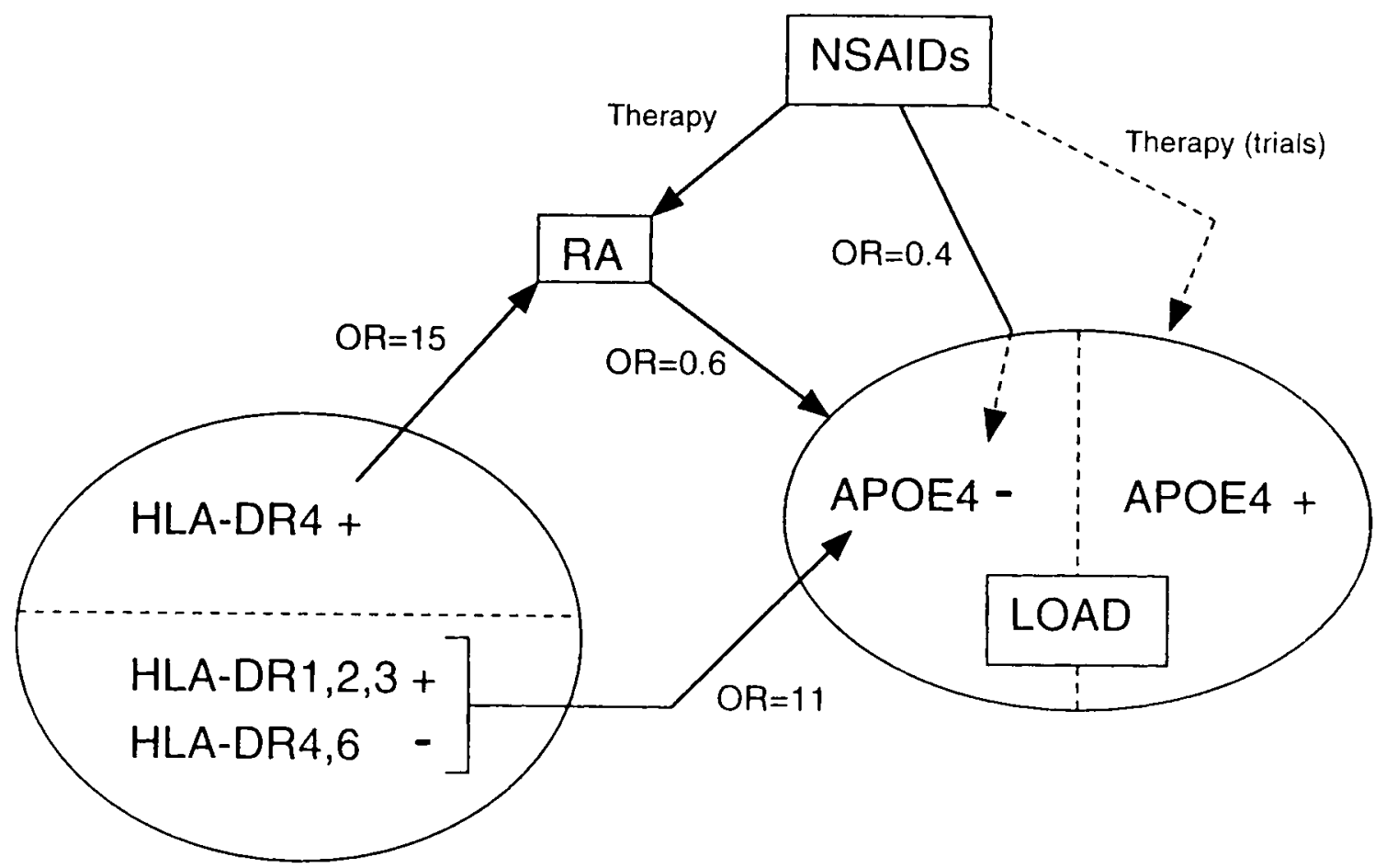

Figure 1. Interaction between genetic and environmental factors in Alzheimer's disease (AD). This scheme represents the association between HLA-DR antigens and late-onset $A D$ and how this might relate to APOE genotype and exposure to NSAIDs. Associations are given as odds ratios (OR), taken from Breitner (1996) and Curran and colleagues (1997). An OR greater than 1.0 represents a positive association and that below 1.0, an inverse association. The arrows point to associations between genetic polymorphisms (HLA-DR or APOE) and disorder (AD or RA) or treatment (NSAIDs). The arrows that do not penetrate the LOAD circle indicate that the inverse association with RA is not dependent on APOE4 genotype. Dotted lines indicate that the NSAIDs' effect shows a tendency to be associated with the protection of patients without an $\varepsilon 4$ allele. Therapeutic trials with NSAIDs are still in progress. This simplified scheme does not take into account other potential confounding factors but serves to demonstrate the complexity of possible interactions between genetic and nongenetic factors that may affect the risk of developing AD. In this example, it is difficult to discern whether the inverse association between AD and RA is due to use of NSAIDs, to the HLA-DR polymorphism, or to a combination of both. NSAID = nonsteroidal anti-inflammatory drug; RA = rheumatoid arthritis; $\mathrm{LOAD}=$ late-onset $\mathrm{AD}$. 
NONGENETIC ENVIRONMENTAL FACTORS

One outcome from the discovery of susceptibility genes is, paradoxically, to assist investigations of environmental factors. Thus in studies of nongenetic risk factors, a knowledge of APOE status may shed light on how we can alter the environment to reduce the incidence of disease. As an example, a potential role of herpes simplex virus (HSV) in the etiology of $A D$ was reported to be dependent on APOE genotype (Itzhaki et al., 1997). The combination of HSV1 in brain and possession of an $\varepsilon 4$ allele presented a strong risk factor for $\mathrm{AD}$, whereas neither of these factors on their own conferred a significant risk.

Evidence for joint effects of genes and the environment is starting to emerge. Possession of an $\varepsilon 4$ allele acts synergistically with head trauma (Katzman et al., 1996; Mayeux et al., 1995) in a situation where increased $A \beta$ deposition in the brain occurs. Head injury is also associated with an unfavorable outcome in patients with an $\varepsilon 4$ allele (Teasdale et al., 1997). An inverse relationship between a history of smoking and early-onset $\mathrm{AD}$ cannot be explained by increased mortality in E4 carriers who smoke. The association is strongly modified by the presence of an $\varepsilon 4$ allele: Among carriers of this allele with a family history of dementia, subjects with a history of smoking had a strongly reduced risk of early-onset $\mathrm{AD}$ (odds ratio .10; Van Duijn et al., 1995).

Drug treatment may be relevant to genetic polymorphisms in two respects. In relation to treatment of $A D$, patients that showed a poor response to tacrine were predominantly those possessing an $\varepsilon 4$ allele (Poirier et al., 1995). The administration of other pharmacological agents may affect processes that occur in both
$A D$ and non-AD patients. Neuroleptics are associated with a greater rate of cognitive decline in $A D$ patients, and it is the E4 carriers who seem particularly susceptible to their effects (Holmes et al., 1997). These observations indicate that APOE genotyping may prove a useful adjunct to therapeutic trials.

\section{CONCLUSIONS}

The discovery of mutations in the APP gene and genes for two presenilin proteins that co-segregate with disease in the earlyonset forms of $\mathrm{AD}$ has provided great advancement toward our understanding of the etiopathogenesis of AD. Nonetheless, the mechanism by which these altered proteins cause $A D$ remains speculative at present. Genes that have a major contribution to the pathogenesis of sporadic lateonset AD are likely to play a crucial role in the development of all forms of $\mathrm{AD}$. The revelation that $\mathrm{APOE}$ genotype provides one such susceptibility factor provides a major step forward. Possession of an APOE $\varepsilon 4$ allele, however, is neither sufficient nor necessary for AD. It is necessary to establish the disease specificity of the APOE association and to take into account as many factors as possible that may confound the analyses. Although APOE4 is an important genetic risk factor for $A D$, it accounted for only a small fraction of disease occurrence in a recent populationbased study (Evans et al., 1997). If the $\varepsilon 4$ allele had not had any effect in this study, then the incidence of AD would have decreased only by less than $14 \%$. Thus it is important that extensive prospective epidemiological studies be performed to assess the interaction between susceptibility genes for $A D$ together with genes that predispose to comorbidity in AD and en- 
vironmental risk factors. As and when other risk factors are identified, their contribution can be assessed both in isolation and in combination with other risk factors. The findings from such investigations will benefit strategies for both preventive and therapeutic treatments for $\mathrm{AD}$.

Alzheimer-type pathology, and neurofibrillary tangles in particular, are changes that are significantly correlated with dementia. The extent to which other genetic or nongenetic variables contribute to the central pathological changes in AD needs to be determined. A knowledge of the order of importance of such variables will hopefully give us a better understanding of the neurodegenerative processes involved in AD.

\section{REFERENCES}

Alberts, M. J., Graffagnino, C., McClenny C., DeLong, D., Strittmatter, W., et al. (1995). ApoE genotype and survival from intracerebral haemorrhage. Lancet, 346, 575.

Arnold, S. E., Joo, E., Martinoli, M.-G., Roy, N., Trojanowski, J. Q., et al. (1997). Apolipoprotein E genotype in schizophrenia: Frequency, age of onset and neuropathologic features. NeuroReport, 8, 1523-1526.

Arriagada, P. V., Marzloff, K., \& Hyman, B. T. (1992). Distribution of Alzheimer-type path-ologic changes in nondemented elderly individuals matches the pattern in Alz-heimer's disease. Neurology, 42, 16811688.

Bétard, C., Robitaille, Y., Gee, M., Tiberghian, D., Larrivée, D., et al. (1994). ApoE allele frequencies in Alzheimer's disease, Lewy body dementia, Alzheimer's disease with cerebrovascular disease and vascular dementia. NeuroReport, 5, 1893-1896.

Blacker, D., Haines, J. L., Terwedow, H., Harrell, L. E., Perry, R. T., et al. (1997). ApoE-4 and age at onset of Alzheimer's disease: The NIMH Genetics Initiative. Neurology, 48, 139-147.
Blennow, K., Bogdanovich, N., Alafuzoff, I., Ekman, R., \& Davidsson, P. (1996). Synaptic pathology in Alzheimer's disease: Relation to severity of dementia, but not to senile plaques, neurofibrillary tangles, or the ApoE4 allele. Journal of Neural Transmission, 103, 603-618.

Blessed, G. (1984). Clinical features and neuropathological correlations of $\mathrm{Alz}$ heimer type disease. In D. W. K. Kay \& G. D. Burrows (Eds.), Handbook of studies of psychiatry and old age (pp. 133-143). Amsterdam: Elsevier.

Brayne, C., Harrington, C. R., Wischik, C. M., Huppert, F. A., Chi, L. Y., et al. (1996). Apolipoprotein $\mathrm{E}$ genotype in the prediction of cognitive decline and dementia in a prospectively studied elderly population. Dementia, 7, 169-174.

Breitner, J. C. S. (1996). The role of anti-inflammatory drugs in the prevention and treatment of Alzheimer's disease. Annual Review of Medicine, 47, 401-411.

Breitner, J. C. S., Welsh, K. A., Gau, B. A., McDonald, L. V. M., Steffens, D. C., et al. (1995). Alzheimer's disease in the National Academy of Sciences-National Research Council Registry of aging twin veterans. III. Detection of cases, longitudinal results, and observations of twin concordance. Archives of Neurology, 52, 763-771.

Corder, E. H., Saunders, A. M., Strittmatter, W. J., Schmechel, D. E., Gaskell, P. C. Jr., et al. (1995). Apolipoprotein E, survival in Alzheimer's disease patients and the competing risks of death and Alzheimer's disease. Neurology, 45, 1323-1328.

Cumming, A. M., \& Robertson, F. W. (1984). Polymorphism at the apolipoprotein-E locus in relation to risk of coronary disease. Clinical Genetics, 25, 310-313.

Curran, M., Middleton, D., Edwardson, J., Perry, R., McKeith, I., et al. (1997). HLADR antigens associated with major genetic risk for late-onset Alzheimer's disease. NeuroReport, 8, 1467-1469.

Davignon, J., Gregg, R. E., \& Sing, C. F. (1988). Apolipoprotein E polymorphism and atherosclerosis. Arteriosclerosis, 8, 1-21. 
Davis, R.E., Miller, S., Herrnstadt, C., Ghosh, S. S., Fahy, E., et al. (1997). Mutations in mitochondrial cytochrome $c$ oxidase genes segregate with late-onset Alzheimer disease. Proceedings of the National Academy of Sciences USA, 94, 4526-4531.

Esiri, M. M. (1994). Dementia and normal aging: Neuropathology. In F. A. Huppert, C. Brayne, \& D. W. O'Connor (Eds.), Dementia and normal aging (pp. 385-436). Cambridge, England: Cambridge University Press.

Evans, D. A., Beckett, L. A., Field, T. S., Feng, L., Albert, M. S., et al. (1997). Apolipoprotein $\mathrm{E} \varepsilon 4$ and incidence of Alzheimer disease in a community population of older persons. Journal of the American Medical Association, 277, 822-824.

Farrer, L. A., Abraham, C. R., Volicer, L., Foley, E. J., Kowall, N.W., et al. (1995). Allele $\varepsilon 4$ of apolipoprotein E shows a dose effect on age at onset of Pick disease. Experimental Neurology, 136, 162-170.

Feskens, E. J. M., Havekes, L. M., Kalmijn, S., DeKnijff, P., Launer, L. J., et al. (1994). Apolipoprotein $\varepsilon 4$ allele and cognitive decline in elderly men. British Medical Journal, 309, 1202-1206.

Finch, C. E., \& Cohen, D. M. (1997). Aging, metabolism, and Alzheimer disease: Review and hypotheses. Experimental Neurology, 143, 82-102.

Frisoni, G. B., Bianchetti, A., Govoni, S., Trabucchi, M., Calabresi, L., et al. (1994). Association of apolipoprotein E E4 with vascular dementia. Journal of the American Medical Association, 271, 1317.

Galasko, D., Saitoh, T., Xia, Y., Thal, L. J., Katzman, R., et al. (1994). The apolipoprotein $E$ allele $\varepsilon 4$ allele is overrepresented in patients with the Lewybody variant of Alzheimer's disease. Neurology, 44, 1950-1951.

Galinsky, D., Tysoe, G., Brayne, C. E., Easton, D. F., Huppert, F. A., et al. (1997). Analysis of the apo E/apo C-I, angiotensin convertingenzyme and methylenetetrahyd rofolate reductase genes as candidates affecting human longevity. Atherosclerosis, 129, 177-183.
Goate, A., Chartier-Harlin, M.-C., Mullan, M., Brown, J., Crawford, F., et al. (1991). Segregation of a missense mutation in the amyloid precursor protein gene with familial Alzheimer's disease. Nature, 349, 704-706.

Gomez-Isla, T., West, H. L., Rebeck, G. W., Harr, S. D., Growdon, J. H., et al. (1996). Clinical and pathological correlates of apolipoprotein E $\varepsilon 4$ in Alzheimer's disease. Annals of Neurology, 39, 62-70.

Greenberg, S. M., Rebeck, G. W., Vonsattel, J. P. G., Gomez-Isla, T., \& Hyman, B. T. (1995). Apolipoprotein E $\varepsilon 4$ and cerebral hemorrhage associated with amyloid angiopathy. Annals of Neurology, 38, 254-259.

Growdon, J.H., Locascio, J. J., Corkin, S., GomezIsla, T., \& Hyman, B. T. (1996). A polipoprotein $\mathrm{E}$ genotype does not influence rates of cognitive decline in Alzheimer's disease. Neurology, 47, 444-448.

Harrington, C. R., Louwagie, J., Rossau, R., Vanmechelen, E., Perry, R. H., et al. (1994). Influence of apolipoprotein $\mathrm{E}$ genotype on senile dementia of the Alzheimer and Lewy body types. Significance for etiological theories of Alzheimer's disease. American Journal of Pathology, 145, 1472-1484.

Harrington, C. R., Roth, M., Xuereb, J. H., McKenna, P. J., \& Wischik, C. M. (1995). Apolipoprotein E type $\varepsilon 4$ allele frequency is increased in patients with schizophrenia. Neuroscience Letters, 202, 101-104.

Henderson, A. S. (1997). The epidemiology of estrogen replacement therapy and $\mathrm{Alz}$ heimer's disease. Neurology, 48 (Suppl. 7), S27-S35.

Henderson, A. S., Easteal, S., Jorm, A. F., MacKinnon, A.J., Korten, A. E., etal. (1995). Apolipoprotein E allele $\varepsilon 4$, dementia, and cognitive decline in a population sample. Lancet, 346, 1387-1390.

Hendrie, H. C., Hall, K. S., Hui, S., Unverzagt, F. W., Yu, C. E., et al. (1995). A polipoprotein $E$ genotypes and Alzheimer's disease in a community study of elderly African Americans. Annals of Neurology, 37, 118-120.

Higuchi, S., Arai,H., Nakagawa, T., Muramatsu, T., Sasaki, H., et al. (1996). The apolipoprotein Egene in Binswanger's disease and 
vasculardementia. Clinical Genetics, 50,459461.

Hofman, A., Ott, A., Breteler, M. M. B., Bots, M. L., Slooter, A. J. C., et al. (1997). Atherosclerosis, apolipoprotein $E$, and prevalence of dementia and Alzheimer's disease in the Rotterdam Study. Lancet, 349, 151-154.

Holmes, C., Fortenza, O., Powell, J., \& Lovestone, S. (1997). Do neuroleptic drugs hasten cognitive decline in dementia? Carriers of apolipoprotein E $\varepsilon 4$ allele seem particularly susceptible to their effects. British Medical Journal, 314, 1411.

Howard, R., Dennehey, J., Lovestone, S., Birkett, J., Sham, P., et al. (1995). Apolipoprotein E genotypeand late paraphrenia. International Journal of Geriatric Psychiatry, 10, 147-150.

Hutchin, T., \& Cortopassi, G. (1995). A mitochondrial DNA clone is associated with increased risk for Alzheimer disease. Proceedings of the National Academy of Sciences USA, 92, 6892-6895.

Hyman, B. T., Gomez-Isla, T., Briggs, M., Chung, H., Nichols, S., et al. (1996). Apolipoprotein $E$ and cognitive change in an elderly population. Annals of Neurology, 40, 55-66.

Isoe, K., Urakami, K., Sato, K., \& Takahashi, K. (1996). Apolipoprotein $\mathrm{E}$ in patients with dementia of the Alzheimer type and vascular dementia. Acta Neurologica Scandinavica, 93, 133-137.

Itzhaki, R. F., Lin, W.-R., Shang, D., Wilcock, G. K., Faragher, B., et al. (1997). Herpes simplex virus type 1 in brain and risk of Alzheimer's disease. Lancet, 349, 241-244.

Kalaria, R. N. (1997). Arteriolosclerosis, apolipoprotein $\mathrm{E}$, and Alzheimer's disease. Lancet, 349, 1174.

Kalaria, R. N., \& Premkumar, D. R. D. (1995). Apolipoprotein $\mathrm{E}$ genotype and cerebral amyloid angiopathy. Lancet, 346, 1424.

Kalmijn, S., Feskens, E. J. M., Launer, L. J., \& Kromhout, D. (1996). Cerebrovascular disease, the apolipoprotein $\varepsilon 4$ allele, and cognitive decline in a community-based study of elderly men. Stroke, 27, 2230-2235.

Kamboh, M. I., Sanghera, D. K., Ferrell, R. E., \& DeKosky, S. T. (1995). APOE*4-associated Alzheimer's disease risk is modified by $\alpha 1$ - antichymotrypsin polymorphism. Nature and Genetics, 10, 486-488.

Katzman, R., Galasko, D. R., Saitoh, T., Chen, X.,Pay,M.M., etal.(1996). A polipoprotein$\varepsilon 4$ and head trauma:Synergistic or additive risks? Neurology, 46, 889-891.

Kervinen, K., Södervick, H., Mäkelä, J., Lehtola, J., Niemi, M., et al. (1996). Is the development of adenoma and carcinoma in proximal colon related to apolipoprotein $\mathrm{E}$ phenotype? Gastroenterology, 110, 1785-1790.

Krishnan, K. R. R., Tupler, L. A., Ritchie, J. C., McDonald, W. M., Knight, D. L., et al. (1996). Apolipoprotein E- $\varepsilon 4$ frequency in geriatric depression. Biological Psychiatry, 40, 69-71.

Kurz, A., Egensperger, R., Haupt, M., Lautenschlager, N., Romero, B., etal. (1996). Apolipoprotein E \&4 allele, cognitive decline, and deterioration of everyday performance in Alzheimer's disease. Neurology, 47, 440-443.

Kuusi, T., Nieminen, M. S., Ehnholm, C.., YkiJärvinen, H., Valle, M., et al. (1989). Apoprotein $E$ polymorphism and coronary artery disease. Increased prevalence of apolipoprotein E-4 in angiographically verified coronary patients. Arteriosclerosis, 9, 237-241.

Kuusisto, J., Koivisto, K., Kervinen, K., Mykkänen L., Helkala, E.-L., et al. (1994). Association of apolipoprotein E phenotypes with late onset Alzheimer's disease: population based study. British Medical Journal, 309, 636-638.

Landén, M., Thorsell, A., Wallin, A., \& Blennow, K. (1996). The apolipoprotein $E$ allele $\varepsilon 4$ does not correlate with the number of senile plaques or neurofibrillary tangles in patients with Alzheimer's disease. Journal of Neurology, Neurosurgery, and Psychiatry, 61, 352-356.

Larkin, M. (1997). Allen Roses: 'Enfant terrible' of Alzheimer's research. Lancet, 349, 1302.

Lehmann, D. J., Johnston, C., \& Smith, A. D. (1997). Synergy between the genes for butyrylcholinesterase $\mathrm{K}$ variant and apolipoprotein $\mathrm{E} 4$ in late-onset confirmed Alzheimer's disease. Human and Molecular Genetics, 6, 1933-1936. 
Leibson, C. L., Rocca, W. A., Hanson, V. A., Cha, R., Kokmen, E., et al. (1997). Risk of dementia among persons with diabetes mellitus: A population-based cohort study. American Journal of Epidemiology, 145, 301-308.

Levy-Lahad, E., Wasco, W., Poorkaj, P., Romano, D. M., Oshima, J., et al. (1995). Candidate gene for the chromosome 1 familial Alzheimer's disease locus. Science, 269, 973-977.

Lippa, C. F., Smith, T. W., Saunders, A. M., Crook, R., Pulaski-Salo, D., et al. (1995). Apolipoprotein E genotypeand Lewybody disease. Neurology, 45, 97-103.

Maestre, G., Ottman, R., Stern, Y., Gurland, B., Chun, M., et al. (1995). Apolipoprotein E and Alzheimer's disease: Ethnic variation in genotypic risks. Annals of Neurology, 37, 254-259.

Mayeux, R.,Ottman, R., Maestre,G.,Ngai,C., Tang, M.-X., et al. (1995). Synergistic effects of traumatic head injury and apolipoprotein$\varepsilon 4$ in patients with Alzheimer's disease. Neurology, 45, 555-557.

McClearn, G. E., Johnansson, B., Berg, S., Pedersen, L., Ahern, F., et al. (1997). Substantial genetic influence on cognitive abilities in twins 80 or more years old. Science, 276, 1560-1563.

Morris, C. M., Massey, H. M., Benjamin, R., Leake, A., Broadbent, C., et al. (1996). Molecular biology of APO E alleles in Alzheimer's and non-Alzheimer's dementias. Journal of Neural Transmission, 47(Suppl.), 205-218.

Myers, R. H., Schaeffer, E. J., Wilson, P. W. F., D'Agostini, R., Ordovas, J. M., et al. (1996). Apolipoprotein E $\varepsilon 4$ association with dementia in a population-based study: The Framingham Study. Neurology, 46, 673-677.

Nagy, Z., Esiri, M. M., Jobst, K. A., Johnston, C., Litchfield, S., et al. (1995). Influence of the apolipoprotein $\mathrm{E}$ genotype on amyloid deposition and neurofibrillary tangle formation in Alzheimer's disease. Neuroscience, 69, 757-761.

Nalbantoglu, J., Gilfix, B. M., Bertrand, P., Robitaille, Y., Gauthier, S., et al. (1994). Predictive value of apolipoprotein $E$ genotyping in Alzheimer's disease: Results of an autopsy series and an analysis of several combined studies. Annals of Neurology, 36, 889-895.

Nathan, B. P., Bellosta, C., Sanan, D. A., Weisgraber, K. H., \& Mahley, R. W. (1994). Differential effects of apolipoproteins E3 and $\mathrm{E} 4$ on neuronal growth in vitro. Science, $264,850-852$.

Nicoll, J. A. R., Burnett, C., Love, S., Graham, D. I., Dewar, D., et al. (1997). High frequency of apolipoprotein E $\varepsilon 2$ allele in hemorrhage due to cerebral amyloid angiopathy. Annals of Neurology, 41, 716-721.

Nicoll, J. A. R., Roberts, G. W., \& Graham, D. I. (1995). Apolipoprotein E $\& 4$ allele is associated with deposition of amyloid $\beta$-protein following head injury. Nature and Medicine, 1, 135-137.

Noguchi, S., Murukami, K., \& Yamada, N. (1993). Apolipoprotein E genotype and Alzheimer's disease. Lancet, 342, 737.

Ohm, T. G., Kirca, M., Bohl, J., Scharnagl, H., Groß, W., et al. (1995). Apolipoprotein E polymorphism influences not only cerebral plaque load but also Alzheimer-type neurofibrillary tangle formation. Neuroscience, 66, 583-587.

Okuizumi, K., Onodera, O., Namba, Y., Ikeda, K., Yamamoto, T., et al. (1995). Genetic association of the very low low density lipoprotein(VLDL) receptor gene with sporadic Alzheimer's disease. Nature and Genetics, 11, 207-209.

Olichney, J. M., Sabbagh, M. N., Hofstetter, C. R.,Galasko, D., Grundman, M., etal.(1997). The impact of apolipoprotein E4 on cause of death in Alzheimer's disease. Neurology, 49, 76-81.

Payami, H., Schellenberg, G. D., Zareparsi, S., Kaye, J., Sexton, G. J., et al. (1997). Evidence for association of HLA-A2 allele with onset age of Alzheimer's disease. Neurology, 49, 512-518.

Petersen, R. C., Smith, G. E., Ivnik, R. J., Tangalos, E. G., Schaid, D. J., et al. (1995). Apolipoprotein E status as a predictor of the development of Alzheimer's disease in memory-impaired individuals. Journal of 
the American Medical Association, 273, 12731278.

Pirttilä, T., Lehtimäki, T., Rinne, J., Mattila, K., Frey, H., et al. (1996a). The frequency of apolipoprotein $\mathrm{E} 4$ allele is not increased in patients with probable vascular dementia. Acta Neurologica Scandinavica, 93, 352-354.

Pirttilä, T., Mehta, P. D., Soininen, H., Kim, K. S., Heinonen, O., et al. (1996). Cerebrospinal fluid concentrations of soluble amyloid $\beta$-protein and apolipoprotein $E$ in patients with Alzheimer's disease: Correlations with amyloid load in the brain. Archives of Neurology, 53, 189-193.

Poirier, J., Delisle, M.-C., Quirion, R., Aubert, I., Farlow, M., et al. (1995). Apolipoprotein $\mathrm{E} 4$ allele as a predictor of cholinergic deficits and treatment outcome in Alzheimer disease. Proceedings of the National Acaderny of Sciences USA, 92, 12260-12264.

Polvikoski, T., Sulkava, R., Haltia, M., Kainulainen, K., Vuorio, A., et al. (1995). Apolipoprotein E, dementia, and cortical deposition of $\beta$-amyloid protein. New England Journal of Medicine, 333, 1242-1247.

Rebeck, G. W., Perls, T. T., West, H. L., Sodhi, P., Lipitz, L. A., et al. (1994). Reduced apolipoprotein $\varepsilon 4$ allele frequency in the oldest old Alzheimer's patients and cognitively normal individuals. Neurology, 44, 1513-1516. [Correction: Hyman, B. T., \& Rebeck, G. W. (1995). Neurology, 45, 589].

Rebeck, G. W., Reiter, J. S., Strickland, D. K., \& Hyman, B. T. (1993). Apolipoprotein E in sporadic Alzheimer's disease: Allelic variation and receptor interactions. Neuron, 11 , 575-580.

Rocca, W. A., Hofman, A., Brayne, C., Breteler, M. M. B., Clarke, M., et al. (1991). The prevalence of vascular dementia in Europe: Facts and fragments from 1980-1990 studies. Annals of Neurology, 30, 817-824.

Rogaev, E. I., Sherrington, R., Rogaeva, E. A., Levesque, G., Ikeda, M., et al. (1995). Familial Alzheimer's disease in kind reds with missense mutations in a gene on chromosome 1 related to the Alzheimer's disease type 3 gene. Nature, 376, 775-778.
Roses, A. D. (1997). Mutational and susceptibility genetics are different clinical paradigms. International Psychogeriatrics, 9, 7-10.

Scacchi, R., De Bernardini, L., Mantuano, E., Donini, L. M., Vilardo, T., et al. (1995). Apolipoprotein E (APOE) allele frequencies in late-onset sporadic Alzheimer's disease (AD), mixed dementia and vascular dementia: Lack of association of $\varepsilon 4$ allele with AD in Italian octogenarians. Neuroscience Letters, 201, 231-234.

Schächter, F., Faure-Delanef, L., Guénot, F., Rouger, H., Froguel, P., et al. (1994). Genetic associations with human longevity at the APOE and ACE loci. Nature and Genetics, 6, 29-32.

Seshardi, S., Drachman, D. A., \& Lippa, C. F. (1995). Apolipoprotein E $\varepsilon 4$ allele and the lifetime risk of Alzheimer's disease. What physicians know, and what they should know. Archives of Neurology, 52, 1074-1079.

Sherrington, R., Rogaev, E. I., Liang, Y., Rogaeva, E. A., Levesque, G., et al. (1995). Cloning of a gene bearing missense mutations in early-onset familial Alzheimer's disease. Nature, 375, 754-760.

Slooter, A. J. C., Tang, M.-X., Van Duijn, C. M., Stern, Y., Ott, A., et al. (1997). Apolipoprotein $\mathrm{E} \varepsilon 4$ and the risk of dementia with stroke. A population-based investigation. Journal of the American Medical Association, 277, 818-821.

Smith, P. G., \& Day, N. E. (1984). The design of case-control studies: The influence of confounding and interaction effects. International Journal of Epidemiology, 13, 356-365.

Sobel, E., Louhija, J., Sulkava, R., Davanipour, Z., Kontula, K., et al. (1995). Lack of association of apolipoprotein $\mathrm{E}$ allele $\varepsilon 4$ with late-onset Alzheimer's diseaseamong Finnish centenarians. Neurology, 45, 903-907.

Sorbi, S., Nacmias, B., Piacentini, S., Repice, A., Latorraca, S., et al. (1995). ApoE as a prognostic factor for post-traumatic coma. Nature and Medicine, 1, 852.

Sparks, D. L., Scheff, S. W., Liu, H., Landers, T., Danner, F., et al. (1996). The increased density of senile plaques (SP), but not neurofibrillary tangles (NFT), in non-demented 
individuals with the apolipoprotein E4 allele: Comparison to confirmed Alzheimer's disease patients. Journal of the Neurological Sciences, 138, 97-104.

Steffens, D. C., Plassman, B. L., Helms, M. J., Welsh-Bohmer, K. A., Saunders, A. M., et al. (1997). A twin study of late-onset depression and apolipoprotein $\mathrm{E}$ e4 as risk factors for Alzheimer's disease. Biological Psychiatry, 41, 851-856.

Stevens, M., Van Duijn, C. M., De Knijff, P., Van Broeckhoven, C., Heutink, P., et al. (1997). Apolipoprotein E gene and sporadic frontal lobe dementia. Neurology, 48, 1526-1529.

Strittmatter, W. J., Saunders, A. M., Schmechel, D., Pericak-Vance, M., Enghild, J., et al. (1993). Apolipoprotein E: Highavidity binding to b-amyloid and increased frequency of type 4 allele in late-onset familial Alzheimer disease. Proceedings of the National Academy of Sciences USA, 90, 1977-1981.

Strittmatter, W. J., Weisgraber, K. H., Goedert, M.,Saunders, A. M.,Huang, D., etal.(1994). Hypothesis: Microtubule instability and paired helical filament formation in the Alzheimer disease brain are related to apolipoprotein E genotype. Experimental Neurology, 125, 163-171.

Sulkava, R., Kainulainen, K., Verkkoniemi, A., Niinisto, L., Sobel, E., et al. (1996). APOE alleles in Alzheimer's disease and vascular dementia in a population aged $85+$. Neurobiology of Aging, 17, 373-376.

Tanzi, R.E., Kovacs, D. M., Kim, T.-W., Moir, R. D., Guenette, S. Y., et al. (1996). The gene defects responsible for familial Alzheimer's disease. Neurobiology of Disease, 3, 159-168.

Teasdale, G. M., Nicoll, J. A. R., Murray, G., \& Fiddes, M. (1997). Association of apolipoprotein E polymorphism with outcome after head injury. Lancet, 350, 1069-1071.

Terry, R. D., Masliah, E., Salmon, D. P., Butters, N., DeTeresa, R., et al. (1991). Physical basis of cognitive alterations in Alzheimer's disease: Synapse loss is the major correlate of cognitive impairment. Annals of Neurology, 30, 572-580.

Todd, J. A., Bell, J. I., \& McDevitt, H. O. (1987). HLA-DQ(b) gene contributes to suscepti- bility and resistance to insulin-dependent diabetes mellitus. Nature, 329, 599-604.

Utermann, G. (1994). The apolipoprotein Econnection. Current Biology, 4, 362-365.

Van Bockxmeer, F. M., \& Mamotte, C. D. S. (1992). Apolipoprotein e4 homozygosity in young men with coronary heart disease. Lancet, 340, 879-880.

Van Duijn, C. M., Havekes, L. M., Van Broeckhoven, C., De Knijff, P., \& Hofman, A. (1995). Apolipoprotein E genotype and association between smoking and early onset Alzheimer's disease. British Medical Journal, 310, 627-631.

Van Gool, W. A., Evenhuis, H. M., Van Duijn, C. M., on Behalf of the Dutch Study Group on Down's Syndromeand Aging. (1995). A case-control study of apolipoprotein E genotypes in Alzheimer's disease associated with Down's syndrome. Annals of Neurology, 38, 225-230.

Wallace, D. C. (1994). Mitochondrial DNA sequence variation in human evolution and disease. Proceedings of the National Academy of Sciences USA, 91, 8739-8746.

Weatherall, D. J. (1991). Newgenetics and clinical practice (3rd ed.). Oxford, England: Oxford University Press.

Wilcock, G. K., \& Esiri, M. M. (1982). Plaques, tangles and dementia: A quantitative study. Journal of the Neurological Sciences, 56, 407417.

Xia, Y., De Silva, H. A. R., Rosi, B. L., Yamaoka, L. H., Rimmler, J. B., et al. (1996). Genetic studies in Alzheimer's disease with an NACP/a-synuclein polymorphism. Annals of Neurology, 40, 207-215.

Zubenko, G. S., Henderson, R., Stiffler, J. S., Stabler, S., Rosen, J., et al. (1996). Association of the APOE e4 allele with clinical subtypes of late life depression. Biological Psychiatry, 40, 1008-1016.

Charles R. Harrington, PhD Martin Roth, MD, ScD, FRCP, FRS Cambridge Brain Bank Laboratory MRC Centre and Trinity College Cambridge, England 